\title{
Buenos Aires: la orientación neoliberal de la urbanización metropolitana
}

\section{Resumen}

Este artículo analiza las transformaciones de la ciudad metropolitana de Buenos Aires con la aplicación de políticas de orientación neoliberal que modificaron las relaciones entre mercado, sociedad y Estado. Buenos Aires ha sido históricamente producida y consumida con predominio de modalidades mercantiles, una relativa prescindencia del Estado, particularmente en lo que hace a suelo y vivienda, y el esfuerzo de los sectores de ingresos medios y bajos. La reestructuración neoliberal, iniciada en 1976, amplió y fortaleció ese predominio: se mercantilizaron procesos no mercantiles, re-mercantilizaron algunos desmercantilizados y la configuración metropolitana se subordinó a orientaciones privadas. Correlativamente, crecieron los procesos no mercantiles populares, de autoproducción e irregularidad, para la producción-consumo de suelo, vivienda y servicios.

Palabras clave: Buenos Aires. Neoliberalismo. Urbanización. Mercantilización. Desmercantilización.

\footnotetext{
* Consejo Nacional de Investigaciones Científicas y Técnicas / Universidad de Buenos Aires (Argentina)
} 


\section{Buenos Aires: the neoliberal orientation of metropolitan development}

\section{Abstract}

This article analyzes the transformations of the metropolitan city of Buenos Aires since the implementation of policies characterized by neoliberal orientation, which changed relations between market, society and the State. Buenos Aires has historically been produced and consumed with predominance of commercial arrangements, a relative disregard by the State, particularly concerning land and housing, and the effort of middle and low income sectors. The neoliberal restructuring, begun in 1976, expanded and strengthened this predominance: uncommodified processes have been commodified, some previously decommodified have been recommodified and the metropolitan configuration became subordinated to private directions. Correspondingly, popular nonmarket processes of self-production and irregularity have developed, for production-consumption of land, housing and services.

Keywords: Buenos Aires. Neoliberalism. Urbanization. Commodification. Decommodification.

\section{Introducción}

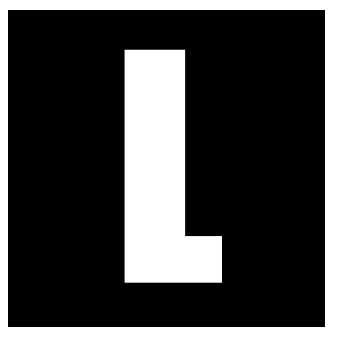

a urbanización capitalista se caracteriza por el predominio de modalidades mercantiles de producción y consumo. Los bienes de la urbanización (suelo, vivienda, infraestructuras, etc.) se producen para satisfacer necesidades (bien de uso) siempre que siendo introducidos en el mercado permitan captar la cantidad de dinero suficiente para cubrir costos y realizar la plusvalía apropiada en la producción (bien de cambio), obteniendo la ganancia de la operación. El consumo de esos bienes depende de la capacidad monetaria (solvencia) de la población para pagar su precio de mercado. Tal solvencia, que depende de la relación entre los 
ingresos y el costo de los bienes a consumir, es una condición relativa: una familia puede ser solvente para adquirir los alimentos cotidianos pero no para acceder al suelo urbano (Pírez 2015).

Las dificultades para la reproducción de la fuerza de trabajo debidas a la existencia de familias insolventes frente a suelo y vivienda, y los conflictos que se generan, fueron enfrentados con intervenciones estatales orientadas a producir de manera no mercantil esos bienes (producción directa para el consumo) o a desmercantilizar, de manera parcial o total, su producción y/o su consumo, disminuyendo las necesidades de recursos monetarios. En ambos casos se utilizó redistributivamente el gasto fiscal, excluyendo la ganancia en la producción y ampliando la solvencia para posibilitar el consumo. La reproducción de la población, no solo de la fuerza de trabajo, quedó en cierto grado sostenida por esos gastos estatales de bienestar.

En el capitalismo dependiente de América Latina, los estados no cumplieron ese papel de bienestar, o lo hicieron limitadamente. La población insolvente frente a la urbanización recurrió a mecanismos por fuera del mercado y del estado. Produjo para su consumo directo los bienes urbanos, en procesos no mercantiles (autoproducción) o fortaleció su solvencia con el apoyo solidario de sus grupos de pertenencia, en procesos de desmercantilización social sin redistribución económica (Pírez 2015).

Antes de iniciar el análisis de Buenos Aires mencionemos que esa área urbana ha sido producida con el predominio del mercado, la participación secundaria (a veces subordinada) del Estado, y un importante esfuerzo de los sectores populares. Es decir, el predominio de modalidades mercantiles, particularmente en la producción-consuno de suelo ${ }^{1}$ y vivienda.

Esa situación no ocurrió únicamente durante la hegemonía de orientaciones liberales (1880-1930), sino aún en períodos considerados de bienestar (1945-1974). La reestructuración neoliberal significó la extensión y

\footnotetext{
${ }^{1}$ En sentido no estricto, ya que el suelo no es un bien resultante de procesos de producción.
} 
fortalecimiento de la producción mercantil, la ampliación del predominio de los capitales particulares, la importancia creciente del capital financiero-inmobiliario y la re-mercantilización de infraestructuras y servicios. Esa reestructuración implicó, así mismo, el fortalecimiento de la producción popular, no mercantil, por autoproducción.

Continuamos con un breve repaso de los antecedentes históricos, para focalizar el análisis de la urbanización metropolitana en las dimensiones de suelo y vivienda e infraestructuras y servicios.

\section{La urbanización metropolitana en Buenos Aires}

La expansión territorial del Área Metropolitana de Buenos Aires (AMBA) se inició en las primeras décadas del siglo XX. Para mediados de siglo tenía 4,7 millones de habitantes, el 63,1 por ciento, poco menos de 3 millones, se concentraba en la ciudad central' ${ }^{2}$, capital nacional (Cuadro 1). Desde entonces la población creció por fuera de la ciudad central. Para 1970 los municipios de la primera corona metropolitana³, los más inmediatos a la ciudad de Buenos Aires, habían recibido la mayor parte del incremento poblacional. Luego el crecimiento se trasladó a la segunda corona $^{4}$, que para 1991 tenía una participación demográfica mayor que la ciudad central (Cuadro 1).

\footnotetext{
${ }^{2}$ Ciudad de Buenos Aires, Capital Federal desde 1880 y autónoma desde 1994. Su territorio es de 200 km2 y en 2010 tenía 2.89 millones de habitantes (Cuadro 1).

${ }^{3}$ La Corona 1 incluye los siguientes municipios: Avellaneda, San Martín, Lomas de Zamora, La Matanza, Lanús, Morón, San Fernando, San Isidro, Tres de Febrero y Vicente López. A comienzo de los años de 1990 el municipio de Morón pierde parte de su territorio y se conforman otros dos municipios: Hurlingham, Ituizango. Su superficie es de 1756 Km2 y en 2010 tenía 5344 mil habitantes (Cuadro 1).

${ }^{4}$ Integrada por los siguientes municipios desde 1970: Almirante Brown, Berazategui, Esteban Echeverría, Florencio Varela, General Sarmiento, Merlo, Moreno, Quilmes y Tigre. En los años noventa el Municipio de General Sarmiento desaparece y se forman tres nuevos municipios: José C. Paz, Malvinas Argentinas y San Miguel. Con una superficie total de 1651 Km2, en 2010 tenía 4409 mil habitantes. (Cuadro 1).
} 
Cuadro 1. Argentina: Población nacional y población del Área Metropolitana de Buenos Aires (AMBA) (No y \%), 1914-2010

\begin{tabular}{|l|c|c|c|c|c|c|c|c|}
\hline & \multicolumn{7}{|c|}{ Años censales } \\
\hline & 1914 & 1947 & 1960 & 1970 & 1980 & 1991 & 2001 & 2010 \\
\hline $\begin{array}{l}\text { Ciudad de Buenos Aires } \\
\text { (CdeBA) }\end{array}$ & 1576597 & 2982580 & 2966634 & 2972453 & 2922829 & 2965403 & 2768772 & 2890151 \\
\hline $\begin{array}{l}\text { Conurbano Bonaerense } \\
\text { (CB) }\end{array}$ & 377741 & 1741338 & 3772411 & 5380447 & 6832545 & 7924424 & 8566037 & 9752993 \\
\hline Primera Corona CB & 273400 & 1409231 & 2787898 & 3672128 & 4293506 & 4614113 & 4726311 & 5344014 \\
\hline Segunda Corona CB & 104341 & 332107 & 984513 & 1708319 & 2539039 & 3310311 & 3839726 & 4408979 \\
\hline $\begin{array}{l}\text { Area Metropolitana de } \\
\text { Buenos Aires (AMBA) }\end{array}$ & 1954338 & 4723918 & 6739045 & 8352900 & 9755374 & 10889827 & 11334809 & 12643144 \\
\hline TOTAL DEL PAIS & 7885237 & 15893827 & 20013793 & 23364431 & 27064000 & 32370298 & 36260130 & 40117096 \\
\hline
\end{tabular}

Fuente: INDEC, Censos de Población y Vivienda.

Esa área, de $3616 \mathrm{Km}^{2}$, se configuró de manera desigual siguiendo dos ejes: norte/sur y centro/periferia ${ }^{5}$. Tanto el centro como el norte fueron, hasta los años noventa del siglo XX, el lugar con mayor cantidad de población de ingresos medios y altos, y de mayor calidad urbana. Ese clivaje se hizo más evidente con la periferia a medida que la urbanización se alejó del centro histórico.

Las desigualdades metropolitanas están asociadas con los distintos tiempos en los que se construyó el territorio metropolitano: la ciudad liberal de fines del siglo XIX hasta los años treinta del siglo XX, la ciudad de la industrialización y el bienestar entre los años cuarenta los setenta del siglo XX y la de la reestructuración neoliberal de mediados de los setenta en adelante.

${ }^{5}$ La ciudad de Buenos Aires se fundó a orillas del Río de la Plata, quedando la ciudad central en el extremo este del área metropolitana. Su crecimiento se dio hacia los otros tres puntos cardinales. 


\section{La ciudad liberal}

La urbanización de Buenos Aires se vincula con la inserción dependiente del país en las relaciones capitalistas, con un modelo agro-exportador articulado con la industrialización británica. La construcción de la ciudad se sustentó en la importante renta rural diferencial que recibía la economía nacional que explica la existencia de grandes palacios privados y públicos, en su sector norte, y conventillos donde se hacinaba la población migrante, fundamentalmente hacia el sur (Pírez 1994 y 2009, Yujnovsky 1974). El mercado fue "el mecanismo de asignación de recursos, y la política del estado, (estaba) orientada a facilitar al máximo el desempeño de las actividades privadas en tierras y en la construcción" (Yujnovsky 1974:330). La renta urbana se captó tanto con el alquiler de habitaciones en conventillos como con el fraccionamiento de suelo periférico. Este se sostuvo en el crecimiento del transporte tranviario y ferroviario que permitió alejarse para comprar tierra en cuotas a largo plazo (Yujnovsky 1974, Torres 2006). Los adquirentes de esos lotes, de diferente superficie y calidad urbana, construyeron sus viviendas, de acuerdo a su capacidad monetaria, por lo general en un medio sin regulaciones estatales y sin urbanizar. El acceso al suelo y la vivienda dependió predominantemente de la solvencia de la población.

En las primeras décadas del siglo XX el Estado buscó garantizar condiciones de higiene, en una orientación de control de la población, y apeló a la filantropía del capital privado para la producción de vivienda social, a la vez que produjo de manera directa una cantidad muy limitada de viviendas para familias de bajos ingresos: 1245 unidades hasta 1943. Al mismo tiempo, otorgó créditos hipotecarios subsidiados, contribuyendo a desmercantilizar la producción en algunos casos y el consumo en otros. Sin embargo, las condiciones de esos créditos dejaban fuera a la mayoría 
de los sectores de menores ingresos necesitados de vivienda (insolvencia) (Yujnovsky 1974:74, 341-349).

Los servicios urbanos se iniciaron como actividades mercantiles, a cargo de capitales extranjeros. Los gobiernos municipales, comenzando por la ciudad de Buenos Aires, trataron de regular la acción de esas empresas, dadas las protestas relativas a los costos y la mala calidad de los servicios (Pírez 2009).

\section{Industrialización y bienestar}

Entre mediados de los años cuarenta y mediados de los setenta del siglo XX predominó un modelo de industrialización sustitutiva de importaciones, con orientación de bienestar y fortalecimiento del mercando interno ${ }^{6}$. Ese cambio de orientación, y la fuerte intervención estatal consecuente, no modificaron las condiciones de producción y consumo de suelo y vivienda, aunque sí lo hicieron con respecto a infraestructuras y servicios (Yujnovsky 1984, Lentini 2008, Pírez 2009). Según Baer y Duarte (2011) entre 1948 y 1954 en el AMBA el Estado construyó de manera directa unas 13 mil viviendas, a las que deben añadirse 7787 unidades construidas, también de manera directa, por el Banco Hipotecario Nacional. Esto es, un total de menos de 21 mil viviendas cuya limitada significación es evidente si tenemos en cuenta que entre 1947 y 1960 el AMBA la población se incrementó a poco más de 2 millones de habitantes (Cuadro

\footnotetext{
${ }^{6}$ Dentro de esa orientación fundamental este período fue políticamente heterogéneo, con diferentes sesgos en la orientación industrializadora: 1946-55 presidencia de Juan Perón, derrocado militarmente ese último año; hasta 1957 gobierno militar; 1958 - 1962 A. Frondizzi electo con exclusión del peronismo; 1962 renuncia Frondizzi por presión militar y se hace cargo el presidente de la Corte J.M. Guido hasta 1963; 1963-1966 A. Illia por elección popular con exclusión del peronismo, es derrocado por un golpe militar; 1966-1973 gobierno militar auto denominado "Revolución Argentina"; 1973 - 1976 elecciones sin exclusiones, gana el peronismo: Presidente Cámpora dos meses y luego es elegido Perón, quien muere en 1974 y es sucedido por la vicepresidenta, su viuda; marzo de 1976 golpe militar.
} 
1), que sustentaron la expansión territorial. Más importante fue la oferta de crédito hipotecario subsidiado que permitió el consumo mercantil de suelo y vivienda a gran cantidad de familias de asalariados, y ayudó a su asentamiento regular (Yujnosky 1984).

La gran expansión metropolitana de esos años fue posible por un conjunto de condiciones que permitieron la configuración de una solvencia popular que sostuvo el acceso regular al suelo. En un contexto de pleno empleo y salarios reales altos, los asalariados disponían de recursos monetarios suficientes para adquirir los lotes que ofrecían promotores privados. En ese período los salarios representaron casi el 45 por ciento de los ingresos sociales. Esa participación fue mayor durante el gobierno peronista (Cuadro 2). La urbanización no regulada hizo posible la venta de suelo sin infraestructuras, servicios, ni equipamientos, con superficies limitadas (Torres 2006, Clichevsky 1990), que podía ser comprado en cuotas en operaciones jurídicamente seguras (Yujnovsky 1984: 76). Algunas intervenciones estatales desmercantilizadoras aumentaron la solvencia de los asalariados: el crédito subsidiado y la gestión incluyente de infraestructuras y servicios estatizados, en particular del transporte ferroviario, que permitió comprar suelo en áreas alejadas del centro. En esos lotes, adquiridos en propiedad formal, ${ }^{7}$ se produjeron viviendas, predominantemente, por procesos de autoproducción (no mercantil) (Clichevsky, 1990: 5; Prévot y Schneier, 1990: 131).

${ }^{7}$ Entre 1947 y 1960, los propietarios aumentaron de 43 a 67\% (Clichevsky, 1999). 
Cuadro 2. Argentina: Participación de los salarios en los ingresos. Promedio anual por período

\begin{tabular}{|c|c|}
\hline Período & Promedio $\%$ \\
\hline $1946-1955$ & 45,42 \\
\hline $1956-1975$ & 43,4 \\
\hline $1946-1975$ & 44,07 \\
\hline $1976-1982$ & 29,14 \\
\hline $1983-1989$ & 31,14 \\
\hline $1991-2001$ & 33,86 \\
\hline $1976-2001$ & 31,78 \\
\hline
\end{tabular}

Fuente: Elaborado por el autor con datos de Basualdo 2010, pp. 35, 122, 203 y 313.

Los convulsionados años posteriores a 1955 vieron disminuir los ingresos reales de los asalariados (Cuadro 2), aunque se mantuvo la industrialización orientada al mercado interno. El financiamiento para la vivienda fue asociado con el ahorro (Yujnovsky 1984:86), con la limitación que ello significó. A inicios de los años setenta se creó el Fondo Nacional de la Vivienda (FONAVI) integrado con aportes provenientes fundamentalmente de los salarios. Hasta principios de la década del 2000 fue el mecanismo fundamental para la producción de vivienda social. ${ }^{8}$

La población no solvente para el loteo popular se asentó en villas de emergencia ocupando suelo de manera ilegal y autoconstruyendo viviendas muy precarias. Esas villas, que habían aparecido en los años treinta, crecieron con la industrialización: para 1956 tenían 112.350 habitantes. Hacia fin del período su aumento había sido mayor: en 1970 residían allí

\footnotetext{
${ }^{8}$ Entre 1972 y 2003 se construyeron por el FONAVI 39.856 viviendas en el AMBA (Varela y Fernández Wagner, 2012: 21), cuando entre 1970 y 2001 la población metropolitana se incrementó en 2.981.909 habitantes (Cuadro 1).
} 
entre 430 mil y 700 mil personas, y en la ciudad de Buenos Aires unas 180 mil (Pírez, 1994:22).

El resultado fue una ciudad que integraba en forma regular, aunque desigual y segregada, a una parte importante de los sectores populares y que, en el caso de quienes no lograban la solvencia necesaria para los procesos regulares, se les permitían usos clandestinos de los bienes urbanos para producir no mercantilmente sus asentamientos.

\section{Orientaciones neoliberales y trasformación metropolitana}

La dictadura de 1976 inició un proceso de reestructuración neoliberal, ${ }^{9}$ imponiendo el disciplinamiento (Canitrot 1979) del conjunto de la sociedad detrás de un modelo de predominio de la inserción internacional y hegemonía del capital financiero ${ }^{10}$. Revirtió la industrialización sustitutiva de importaciones, provocando desempleo y deterioro de la distribución económica, con gran caída de los ingresos reales. La participación de los asalariados en todo el período (1976-2001) fue menor al 32 por ciento, y durante los años de la dictadura no alcanzó el 30 por ciento (Cuadro 2).

El gobierno central se retiró de las políticas más importantes en infraestructura, salud y educación, descentralizando hacia los gobiernos provinciales, en un contexto de disminución del gasto público, baja del gasto social y brutal represión política y social (Basualdo 2010, Pucciarelli 2004).

\footnotetext{
${ }_{9}^{9}$ Podemos sintetizar esa orientación en tres rasgos fundamentales: apropiación por el capital de cada vez mayor excedente, aumentando la productividad y la explotación, con reestructuración del proceso de trabajo y del mercado laboral; cambio en el modelo de intervención estatal, en detrimento de la legitimación y la redistribución, e internacionalización de los procesos económicos para incrementar rentabilidad y abrir mercados (Castells, 1995: 52-57). ${ }^{10}$ La dictadura buscó "restablecer el orden capitalista modificando drásticamente la estructura económica y social para disolver las bases materiales de la alianza entre la clase trabajadora y la burguesía nacional y, de esa manera, restablecer relaciones de dominación permanentes en el tiempo." (Basualdo 2010: 116. Énfasis en el original)
} 
La imposibilidad de consolidar el proyecto neoliberal, junto con las contradicciones sociales y políticas que emergieron, sumados a la crisis política derivada de la derrota en la guerra de Malvinas, obligó al gobierno militar a llamar a elecciones en 1983. La posterior crisis económica provocada por las políticas aplicadas hasta entonces fue heredada por el gobierno de Raúl Alfonsín que, dada la debilidad estatal no pudo suportarla y debió entregar anticipadamente el cargo al ya electo presidente Carlos Menem. Este completó la orientación iniciada por la dictadura sometiendo al conjunto de la sociedad a una fuerte reestructuración, comenzando por la reforma del Estado y de la economía. La modificación del papel estatal debilitó la aplicación de políticas y recursos para la población de bajos ingresos, y se orientó a la promoción de los negocios en diferentes campos (entre ellos el inmobiliario). ${ }^{11}$ Diez años de gobierno de Menem (1989-1999) dejaron una marca fundamental en el conjunto de la sociedad y en la ciudad metropolitana de Buenos Aires.

Los cambios en el mercado de trabajo fortalecieron algunos pocos puestos de gran calificación y altas remuneraciones, deterioraron las ocupaciones industriales, promovieron el desempleo y el aumento de las desigualdades en la distribución del ingreso, hacia una creciente polarización. Se conformó una clase media alta con fuertes ingresos y gran capacidad de consumo y, como contraparte, aumentó la población bajo la línea de pobreza, con brechas cada vez más amplias y el debilitamiento de la clase media tradicional. Entre 1991 y 2002 la diferencia entre los recursos recibidos por $20 \%$ de la población con menores ingresos y el $20 \%$ de la población con mayores recursos pasó de 9.2 a 14.5 veces. Entre esos años

\footnotetext{
${ }^{11}$ El Estado posibilitó grandes operaciones inmobiliarias con excepciones al Código de Planeamiento en la entonces Municipalidad de Buenos Aires, y con la promoción de grandes proyectos como la construcción de un nuevo barrio en el Antiguo Puerto Madero, la renovación de la zona del Mercado de Abasto o los proyectos frustrados de Retiro y Ciudad Judicial (Cuenya 2012).
} 
la población bajo la línea de pobreza se incrementó de 27.4\% a 52.4\% (Basualdo 2010, Ciccolella 2000, Pírez, 2004).

La orientación económica y las principales acciones estatales transformaron la producción de la urbanización. Aparecieron nuevos actores económicos con gran poder de decisión sobre la configuración metropolitana que superan la capacidad de regulación y control de los consumidores y del Estado ${ }^{12}$, en particular en los servicios urbanos (Pírez, 1994 y 1999; Pírez et al., 2003) y en la producción del suelo ${ }^{13}$. La emergencia de las clases medias altas aseguró un mercado adecuado para nuevos productos urbanos, a la vez que los grupos de menores ingresos vieron afectada su limitada solvencia por la disminución de la oferta accesible de bienes urbanos ${ }^{14}$, cuando crecían el desempleo y la pobreza. Consecuentemente, se incrementó la producción directa, no mercantil, de la ciudad.

Concentramos el análisis en los cambios ocurridos en la producción de suelo e infraestructuras urbanas en la expansión metropolitana.

Fin de la solvencia popular y crecimiento de la autoproducción no mercantil

Las políticas de orientación neoliberal eliminaron las condiciones que permitían la solvencia popular y, consecuentemente, dejaron sin base al submercado del loteo popular y a la posibilidad de acceso regular de los sectores populares a la urbanización.

Las políticas económicas provocaron desempleo y disminución de los salarios, con lo que se alteró la dimensión de los ingresos en la sol-

\footnotetext{
${ }^{12}$ Esto resulta de la concentración y centralización del capital promovidas por las políticas aplicadas desde principios de los 90 (Basualdo 2010)

${ }^{13}$ Un caso interesante es la empresa inmobiliaria IRSA que creció de manera exponencial (Socoloff 2013).

${ }^{14}$ Se eliminó prácticamente el FONAVI y se privatizó el Banco Hipotecario y los servicios urbanos.
} 
vencia popular. A ello se sumó la modificación del costo de los bienes urbanos, que fueron afectados por medidas económico-sectoriales, como la eliminación del congelamiento de los alquileres urbanos y la indexación de las deudas de los contratos de compraventa que incluyó a los loteos populares. Igualmente, la erradicación (autoritaria y represiva) de la mayor parte de las villas de la ciudad central incrementó la presión sobre las tierras de los municipios metropolitanos ${ }^{15}$. En 1976 se suspendió la subdivisión de loteos en esos municipios y en 1977 se reguló el ordenamiento territorial y el uso, subdivisión, ocupación y equipamiento del suelo. Se hizo obligatoria la provisión de infraestructura básica y equipamientos, así como superficies mínimas de los lotes (Decreto Ley 8912). La consecuencia inmediata fue la limitación de los loteos y el encarecimiento de la tierra (Clichevsky, 1999).

La política de vivienda de la dictadura consolidó las tendencias anteriores, orientándose hacia dos tipos de beneficiarios. Las familias con necesidad de financiamiento a largo plazo y con intereses mínimos, pero con capacidad de ahorro (solvencia para crédito formal) para quienes se destinaron las acciones del Banco Hipotecario Nacional; y las familias insolventes para acceder a esos créditos, a quienes se orientaron las acciones del FONAVI, que fuera reorganizado en 1977 (Yujnovsky 1984). De todas maneras, ya conocemos la limitada producción de viviendas de esa institución ${ }^{16}$.

Con la pérdida de la solvencia popular y la desaparición del submercado de loteos populares, dejó de existir una oferta legal de suelo para los pobres urbanos y éstos debieron resolver por sí mismos esa necesidad. En los años ochenta comenzó la toma ilegal de tierras públicas y privadas

\footnotetext{
${ }^{15}$ En 1977 la población asentada en villas en la ciudad de Buenos Aires se había incrementado hasta las 280 mil personas, pero luego de la erradicación, en 1981, residían allí solamente 14 mil villeros (Pírez 1994:22).

${ }^{16}$ Ver nota 8.
} 
y la formación de "asentamientos"17 (Merklen, 2005 y 2009). La población excluida se organizó para ocupar tierras y construir loteos a partir de una previa planificación que sustituía la acción estatal y se orientaba a la satisfacción directa de su necesidad. El acceso al suelo de manera no mercantil, superados los intentos de expulsión represiva, se continuó con la construcción de los componentes de la urbanización, privados como vivienda o públicos como equipamientos, infraestructuras y servicios.

Esas alternativas no mercantiles, sin embargo, no permitieron superar el bajo nivel del hábitat popular, tanto en términos formales (ocupación ilegal, loteos clandestinos) como urbano-ambientales (áreas inundables y contaminadas, sin infraestructuras ni servicios, pésima accesibilidad, sin conexión con áreas centrales, etcétera).

Se consolidó un universo irregular localizado predominantemente hacia la periferia, que promovió la expansión metropolitana en búsqueda de tierras para asentarse. Para fines de los años noventa más de un millón de personas ${ }^{18}$ vivían en condiciones de irregularidad legal y de precariedad urbano-ambiental, mientras continuaban las invasiones (Clichevsky, 1999) ${ }^{19}$.

La tensión mercantilizadora llegó también a la ciudad auto-producida no mercantilmente, donde se desarrolló un mercado inmobiliario informal (de venta o alquiler) que, si bien con características diferentes al mercado formal, introdujo esos bienes urbanos en relaciones de intercambio monetario, requiriendo para su consumo cierta solvencia (Cravino 2006).

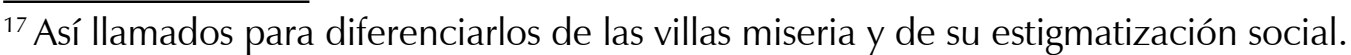

${ }^{18}$ Aproximadamente $10 \%$ de la población del área.

${ }^{19}$ En los años ochenta es irregularidad comenzó a ser enfrentada con acciones de regularización dominial (Clichevsky, 1999), que no se hicieron cargo de las condiciones económicas de la población, que veía aumentar sus gastos: pago de la tierra, impuestos prediales y tasas municipales, y costos de los servicios urbanos privatizados.
} 
El mercado inmobiliario para los sectores medios y altos: urbanizaciones cerradas, privatización y fragmentación urbana

Las políticas aplicadas desde mediados de los años setenta y, particularmente, en los noventa de siglo XX, modificaron las condiciones del mercado inmobiliario, también, para los sectores medio-altos y altos. El resultado fue una tendencia al fortalecimiento de los procesos mercantiles que consolidaron la suburbanización de esas clases. ${ }^{20}$

Hasta los años noventa del siglo XX los grupos de altos recursos de Buenos Aires residían casi exclusivamente en el centro, que mantenía gran calidad urbana. Con las orientaciones neoliberales, aparecieron condiciones que provocaron su suburbanización, y la configuración de un territorio diferenciado, desigual y fragmentado.

Como vimos se formó una clase media alta con gran capacidad de consumo $^{21}$ inserta en las actividades ligadas al mercado global (finanzas, servicios a las empresas, servicios urbanos privatizados, etc.), que desarrolló un estilo de vida ostentoso como un elemento de identidad, que se concretaba principalmente en residencia y automóvil. Al mismo tiempo, la producción pública de la ciudad, crecientemente debilitada, se alejó cada vez más de sus expectativas.

En los años noventa se consolidó la industria automotriz como un sector clave para la generación de empleo, la composición del producto y, gracias a los acuerdos del Mercosur, especialmente con Brasil, para la

\footnotetext{
${ }^{20}$ En los primeros trabajos sobre el tema, Horacio Torres se refiere a la "suburbanización de las élites" (Torres,

${ }^{21}$ Entre 1998 y 2001, el 20\% de la población de mayores ingresos recibió 45,8; 45,4; 46,4 y $47,3 \%$ del total de los ingresos metropolitanos (INDEC, EPH, Onda Mayo).
} 
exportación ${ }^{22}$. El incremento de la producción alimentó el consumo local, dando lugar a la automovilización de la sociedad metropolitana ${ }^{23}$.

A comienzos de los años noventa se privatizaron las redes viales trocales que vinculaban la ciudad capital, centro metropolitano, con el conjunto del país. En ese proceso se transformaron los accesos a la ciudad de Buenos Aires, resultando posible conectar rápidamente el centro metropolitano con la periferia más lejana, utilizando los automóviles privados ${ }^{24}$.

Las políticas económicas, así como la aparición de nuevos actores y la transformación de algunos existentes, provocaron el cambio de las condiciones de la producción mercantil de la urbanización. Los actores que producen suelo se profesionalizan y concentran, e intervienen capitales y tecnologías extranjeros (Mignaqui y Szajnberg, 2003). Se inician fuertes campañas de marketing ${ }^{25}$ que fortalecen el prestigio de la residencia suburbana cerrada como parte de un estilo accesible para quienes tienen altos ingresos.

El fin del loteo popular había dejado suelo periférico vacante que pudo utilizarse para construir esas nuevas urbanizaciones. En un comienzo se desarrollaron country clubs, destinados a la residencia de fin de semana, y cementerios jardín (Prévot y Schneier, 1990: 124); luego se consolidó la producción de diferentes modalidades de urbanizaciones cerradas $^{26}$ para residencia permanente. Estas se complementaron con lu-

${ }^{22}$ La exportación de material de transporte pasó de 190,1 millones de dólares en 1989 a 2.785,8 millones en 1997 (Rapoport 2005:811).

${ }^{23}$ Según datos del Gobierno de la ciudad de Buenos Aires, entre 1996 y 2001 se empadronó un promedio de 1.472.393,5 de vehículos anualmente (26/10/2015): http://www.buenosaires. gob.ar/areas/hacienda/sis_estadistico/anu_estadistico/17/web17/171.htm

${ }^{24} \mathrm{El}$ crecimiento del uso del automóvil se refleja en su participación en el total de los viajes metropolitanos: mientras en 1970 representaban el 15,5\% en 2010 eran el $18 \%$ de los viajes. Ese incremento fue de $16 \%$, mientras los medios colectivos (tren, metro y bus) disminuyeron un $26 \%$ (Gutiérrez 2015:320).

${ }^{25}$ Un buen ejemplo es la publicación en los dos diarios más importantes del área metropolitana (Clarín y La Nación) de suplementos semanales destinados a ese mercado, cubriendo además de lo inmobiliario, información sobre construcciones, insumos para la vida suburbana, con información sobre la vida social, deportiva y cultural de esos "barrios".

${ }^{26}$ Barrios cerrados, ciudades cerradas, marinas, chacras, etc. 
gares especiales para el comercio, la recreación y algunos servicios como los educacionales. Para ello se utilizaron también tierras con restricciones ambientales, como humedales que fueron objeto de obras importantes para permitir las construcciones y que alteraron las condiciones naturales de esas áreas (Ríos y Pírez 2008).

Las ocupaciones de suelo que mencionamos fueron permitidas por la debilidad normativa y la ausencia de reglas metropolitanas. Más aún, fueron promovidas por la adecuación de las disposiciones del Decreto-Ley 8912 por el gobierno provincial, que facilitó esos nuevos usos del suelo (Mignaqui y Szajnberg, 2003), como por una favorable aplicación de parte de algunos municipios metropolitanos.

Para fines del siglo XX había entre 300.000 y 500.000 personas residiendo en unas 400 unidades de esa naturaleza (Janoschka, 2003). Son particularmente significativas las llamadas ciudades pueblos o megaurbanizaciones cerradas, de entre 400 y 1,600 hectáreas, que incluyen varios barrios, con más de 2.000 viviendas y con una población potencial de cerca de 200 mil personas en la más grande (Nordelta) (Janoschka, 2002; Vidal-Koppmann, 2004). En muchos casos, esas nuevas urbanizaciones colindan con barrios precarios, tanto de los históricos loteos populares como los más recientes "asentamientos".

El resultado fue un ámbito urbano desigual, segregado y altamente vigilado que introdujo discontinuidad en el tejido urbano, fragmentando el espacio metropolitano, con fronteras difíciles de atravesar. Esos territorios cerrados ofrecen infraestructuras, servicios urbanos (redes de electricidad, gas, teléfono, internet, pavimentos, alumbrados, mantenimiento, espacios verdes, vigilancia), áreas comerciales y recreativas, oficinas, servicios educativos y centros médicos y culturales. Configuran excluyentes fragmentos privados de alta calidad.

Las mencionadas operaciones re-configuraron la periferia metropolitana y promovieron la penetración de los intereses privados en la 
planificación de ese territorio. Esto está asociado al peso creciente que adquirieron los actores privados en la orientación de la urbanización metropolitana (Janoschka, 2002, Ríos y Pírez 2008). Sus emprendimientos resultan de una planificación empresaria que sustituye a la inexistente o débil planificación estatal. La consecuencia fue una racionalización mercantil de operaciones individuales, con fuerte planificación interna de sus componentes y un sistema de control del cumplimiento, con la finalidad de aumentar la calidad del producto inmobiliario y, particularmente, de incrementar su rentabilidad. Al mismo tiempo, esa operación implico el desconocimiento del resto de la ciudad.

En tono con lo anterior, los municipios trataron de resolver las cuestiones que provocaba la localización de esas urbanizaciones, atendiendo a intereses particulares, económicos y políticos, en razón de su percepción de las ventajas asociadas con las propuestas privadas, y con su capacidad para facilitarlas (Ríos y Pírez 2008).

El proceso anterior introdujo dos nuevas miradas en la producción de la urbanización: entender la producción de una parte de la ciudad como producción de la ciudad (el todo), desconociendo que se da dentro de una ciudad real que provee las condiciones de su existencia, aunque sea autoexcluida (fuentes de trabajo, infraestructuras troncales, servicios generales, etc.); y definir el desorden urbano que caracteriza a la ciudad real, desde la experiencia de vida en esos lugares, invisibilizando la falta de condiciones para el asentamiento de la población de menores recursos. El resto de la ciudad, que sustenta a las urbanizaciones cerradas, se percibe, en todo caso, como condición de la vida excluida de ella misma.

El resultado final es una urbanización que desconoce la planificación urbana pública, y no tienen en cuenta otra racionalidad que la del mercado. La ciudad como la suma de operaciones privadas, y de sus intersticios, en un medio (la ciudad real) que no se percibe como objeto de acción. 
Esa modalidad se concreta en un sistema normas que emanan de un documento privado (contrato de compra-venta) y se imponen como cláusulas de adhesión. Normas urbanas (zonificación, uso del suelo, edificación); normas de comportamiento social, reglamentos de ética y de convivencia que funcionan como un derecho de admisión (o de exclusión), con el uso de instrumentos mercantiles para lograr finalidades sociales que consolidan la identidad uniforme de cada proyecto. Los recursos naturales se subordinan a la valorización del emprendimiento, con uso dilapidatorio del suelo y una utilización arbitraria del área ocupada, sin control público del impacto que suponen para áreas más amplias donde residen otras poblaciones (Ríos y Pírez 2008).

Se reproduce la lógica global del mercado: en un contexto externo de competencia, dura racionalidad en cada unidad individual buscando calidad para algunos $y$, consecuentemente, alta rentabilidad.

\section{La re-mercantilización de las infraestructuras urbanas}

Entre los años cuarenta y cincuenta del siglo XX, las infraestructuras metropolitanas (agua y saneamiento, electricidad, gas, transporte ferroviario de superficie y subterráneo, teléfonos) fueron estatizadas y centralizadas: dejaron de ser reguladas y controladas por los gobiernos locales (de la ciudad de Buenos Aires y los municipios metropolitanos) que las habían dado en concesión a empresas privadas de capital extranjero, y quedaron a cargo de empresas estatales del nivel federal. Para fines de los años ochenta su deterioro era tal (en gran medida debido a la mala gestión de la dictadura) que presentaban baja cobertura territorial y social, problemas financieros e incapacidad de realizar inversiones, mala calidad y, en algunos casos, corrupción en sus relaciones con sindicatos y empresas privadas proveedoras. La gestión estatal fue, en general, permisiva con los consumos clandestinos de la población de bajos recursos, evitando en cierta medida su exclusión del servicio (Pírez, 1999 y 2009). 
Con las reformas a inicios de los años noventa se produjo una veloz e integral transferencia ${ }^{27}$ de infraestructuras y servicios a empresas privadas con importante peso de capitales internacionales. Ello ocurrió con la gestión de las redes telefónicas, de electricidad y gas natural, agua y saneamiento; los transportes ferroviarios de superficie y subterráneos (los autobuses ya lo eran), y la vialidad de acceso a la ciudad (Pírez 1999 y 2009, Pírez et al 2003).

Esas transferencias significaron la re-mercantilización de los servicios: su orientación por la ganancia hacia el consumo solvente. El ciudadano-usuario pasó a ser cliente con derechos sobre el producto como equivalente del precio pagado. El Estado se limitó a asegurar el cumplimiento de las relaciones mercantiles, aun en su desigualdad.

Los servicios dejaron de ser públicos en el sentido de un derecho, para ser actividades económicas reguladas. Su gestión dejó de lado una supuesta orientación de universalidad, que no se concretaba en los hechos, y se impuso su prestación obligatoria: las empresas no pueden negarlos a quienes cumplen con las condiciones legales (proximidad a las redes existentes y pago de las cantidades monetarias establecidas). Mejoraron su calidad y aumentaron su eficiencia, pero el incremento de las tarifas tendió a dejar fuera a la población de menores recursos ${ }^{28}$. Las empresas prestadoras se convirtieron en actores con gran peso económico y político, no solamente por su importancia sectorial sino por la debilidad de los marcos de regulación y de los organismos de control. En algunos casos se sumaron las presiones de los gobiernos de los países de origen.

\footnotetext{
${ }^{27}$ En diferentes modalidades que no es relevante desarrollar.

${ }^{28}$ En las distribuciones de electricidad y gas natural se prohibieron los subsidios cruzados, con el argumento de que cada quien debe pagar su consumo.
} 
La privatización contribuyó con la concentración y las exclusiones económicas y sociales, pues la regulación limitó el riesgo empresario y permitió altas tasas de rentabilidad ${ }^{29}$ (Aspiazu y Schorr, 2003: 21). Por ejemplo, indexaciones basadas en la inflación de Estados Unidos ${ }^{30}$ (prohibidas legalmente), dolarización y sucesivas renegociaciones de limitada legalidad, permitieron el crecimiento de las tarifas muy por encima de la inflación local ${ }^{31}$. Las tarifas de los usuarios residenciales de gas y electricidad aumentaron más que las de los grandes usuarios, introduciendo un sesgo regresivo (Aspiazu y Schorr, 2003: 19).

El incremento de las tarifas sumado a la limitación de los subsidios y la eliminación de la permisividad del uso clandestino, dificultó el acceso y permanencia en los servicios de la población de bajos ingresos (Pírez, 2000). El incremento tarifario alteró, también, las condiciones de las actividades económicas afectando la competitividad, en especial, de las pequeñas y medianas empresas (Aspiazu y Schorr, 2003: 38).

Las empresas privadas no solamente abandonaron la actitud permisiva frente a consumos clandestinos, sino que presionaron para "disciplinar" a los usuarios. La regulación estableció mecanismos para ello. La relación empresas-usuarios clandestinos no requiere intervención de autoridad gubernamental, y es llevada discrecionalmente por las empresas, pudiendo convenir soluciones diferentes para casos análogos. Los organismos gubernamentales solamente intervienen si emerge un conflicto. El Estado se limita a ejercer el poder de policía sobre las adjudicatarias, en

\footnotetext{
${ }^{29}$ Entre 1993 y 1997, la cúpula empresarial argentina obtuvo una rentabilidad promedio de $5 \%$, mientras que la distribución del gas logró una de $11.6 \%$, y las telefónicas, una de $15.6 \%$ (Pírez, 2000: 51).

${ }^{30}$ Entre septiembre de 1996 y diciembre de 2001, el Índice de Precios al Consumidor en Estados Unidos se incrementó en 12\%, mientras que en Argentina sufrió una deflación de 3\% (Aspiazu y Schorr, 2003: 24).

${ }^{31}$ La tarifa de agua, por ejemplo, se incrementó 88.2\% entre mayo de 1993 y enero de 2002, mientras que el Índice de Precios al Consumidor aumentó 7.3\% (Aspiazu y Schorr, 2003: 32).
} 
un escenario donde el cliente está supeditado al poder de las empresas en una relación asimétrica (Pírez 2000 y 2009).

La población de bajos recursos vio incrementada su insolvencia frente a los servicios ${ }^{32}$. El peso de esos rubros en los presupuestos familiares aumentó de manera inversamente proporcional al volumen de los ingresos. La información para antes y después de las privatizaciones (1988 y 1996-97) indica que la población en su conjunto destinó antes el $9 \%$ de su gasto a la vivienda y el $13.1 \%$ nueve años después. Las familias del quintil de menor ingreso destinaron aproximadamente dos veces más que el promedio, y más de tres veces que las familias del quintil de mayores ingresos (Pírez, 2009). La dinámica de las tarifas tuvo también su peso: en agua y saneamiento se incrementaron de manera inequitativa, entre 1993 y 2002 la tarifa mínima aumentó 177\%, la factura promedio lo hizo en $62 \%$ y la de los usuarios de mayor facturación individual subió solamente el 44\% (Azpiazu, 2010).

Con las privatizaciones, las empresas privadas obtuvieron la capacidad de definir la política y la planificación de las infraestructuras, además de las de los servicios. Esto les dio un papel clave en la configuración urbana (Pírez et al., 1999). Las decisiones sobre dónde extender la infraestructura, qué servicio producir y en qué orden temporal hacerlo dependieron, obviamente, de las orientaciones mercantiles de las empresas. Cuando se privatizó el servicio de agua y saneamiento las principales necesidades eran el tratamiento de aguas servidas y la expansión de la red de saneamiento; pero la empresa privilegió la red de agua y no amplió el muy limitado tratamiento del agua servida. Era evidente la mayor facilidad de venta del agua respecto de las cloacas, mientras que el tratamiento del agua no implicaba nuevos ingresos.

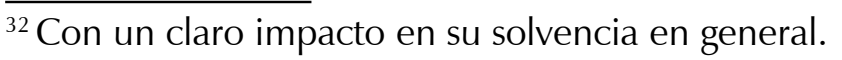


Al dejar el Estado de cumplir un rol planificador, la orientación de las infraestructuras dependió de las relaciones de mercado resolviéndose con base en el poder de decisión privado. Esas decisiones, además, se reprodujeron en el territorio metropolitano, afectando tanto al mercado del suelo como a la calidad de vida.

\section{Conclusiones}

En Buenos Aires ha sido constante el predominio de la producción y consumo mercantiles de la urbanización, y la consecuente presencia de formas de producción-consumo popular no mercantil. El peso de las orientaciones neoliberales, desde 1976 y, particularmente, en los años noventa, no implicó una modificación radical de esa tendencia, sino que la fortaleció polarizando la urbanización entre formas mercantiles y no mercantiles, debilitando la desmercantilización estatal, y eliminando la producción estatal no mercantil. El territorio se diferenció en áreas de extrema desigualdad, muchas veces colindantes en situaciones de "microfragmentación": una calle, o un muro, puede separar una urbanización cerrada de alto nivel de un asentamiento popular precario.

Dos fueron los orígenes principales de esas modificaciones.

Por una parte, el fin de la solvencia popular que había permitido el asentamiento regular de la población de bajos ingresos. Terminó la oferta de suelo barato regular, y aumentó su producción no regular para el consumo directo (no mercantil). Esto se complementó con la eliminación de las protecciones que existían para el asentamiento de los sectores populares. Desde aquellas formales, como los subsidios, hasta las informales como la permisibilidad del consumo clandestino de suelo, vivienda, infraestructuras y servicios. Por el contrario, esas orientaciones fueron sustituidas por el disciplinamiento mercantil destinado a garantizar la segu- 
ridad jurídica de la propiedad y consolidar la ganancia. En una paradoja coherente, el fin de la permisividad para las familias de bajos ingresos fue sustituida por cierta permisividad, igualmente en el borde o al margen de la legalidad, para con las empresas que producen mercantilmente suelo $y$, particularmente, infraestructuras y servicios.

Por otra parte, el fortalecimiento de la mercantilización se concretó nuevos objetos urbanos para los sectores de ingresos medios y altos: urbanizaciones cerradas que se localizaron tendencialmente en la periferia metropolitana. Esta se caracterizó por la emergencia de áreas de expansión que polarizan las ocupaciones, como vimos, en una tendencia de fragmentación y, aún, de micro fragmentación. La operación mercantil no solamente cumplió un papel económico, en el sentido de garantizar negocios inmobiliarios muy rentables, sino que funcionó como mecanismo de diferenciación: fuerte segregación, por un lado respecto de la ciudad real que sostiene a las urbanizaciones privadas, y por el otro entre quienes están fuera de la ciudad, dentro de la identidad territorial amplia, en razón de la diferencial distribución interna ("barrios"). La población solvente se estratifica y distribuye en el espacio metropolitano de manera coherente con su desigual capacidad económica. Esta diferenciación se da en dos registros: en la ciudad en su conjunto y dentro de las áreas de exclusión, en una suerte de exclusión de segundo grado.

La tensión hacia la expansión metropolitana, que se dio en los años noventa e inicio de los dos mil, estuvo motorizada de manera heterogénea en razón de esas dos tendencias desiguales de ocupación del territorio. Por un lado, la búsqueda de suelo mercantilmente poco relevante, no solamente barato, sino con algun impedimento para su fácil incorporación en el mercado, para que las ocupaciones irregulares fueran lo menos contradictorias posibles y, por ende, pudieran sostenerse. Por otro lado, para que el bajo precio de esas tierras permitiera la alta rentabilidad de las urbanizacio- 
nes mercantiles. Estas últimas utilizaron, y dilapidaron, suelo más allá de los setenta kilómetros del centro histórico, con alta rentabilidad.

La urbanización quedó subordinada a la acumulación de capital, dependiendo de decisiones de los productores privados en la incorporación de suelo, la producción de infraestructuras y la prestación de servicios. La naturaleza quedó igualmente subordinada: se ocupó tierra vulnerable, con obras que alteraron los flujos hídricos y las recargas acuíferas.

Si bien no entra dentro del objetivo de este trabajo, no podemos dejar de mencionar, de manera muy breve, que lo que ha sido considerado el "momento" neoliberal en la sociedad argentina, y que ha afectado a la ciudad metropolitana de Buenos Aires como hemos indicado, habría tenido un en los primeros años de la década del 2000. Particularmente la Argentina cambió luego de 2003. Se inició un proceso de re-industrialización para el mercado interno y se revirtieron muchas de las políticas de los años noventa: redistribución económica, uso de subsidios, renegociación de la deuda externa y desendeudamiento, re-estatización de jubilaciones y de empresas privatizadas, fortalecimiento de derechos humanos y muchas más. La producción de la ciudad no fue objeto de una reformulación análoga, más allá de que se destinaran programas y recursos a fortalecer la solvencia de los sectores de bajos ingresos y algunos a facilitar la producción no mercantil popular. Quizás lo más relevante fuera la sanción por la Provincia de Buenos Aires de una ley llamada de acceso justo al hábitat, modificando las normas del suelo existentes en un sentido de función social de la propiedad, sienta las bases para que los municipios metropolitanos puedan elaborar políticas inclusivas del suelo.

Sin embargo, a fines de 2015 y por un margen estrecho de votos en la segunda vuelta de las elecciones presidenciales, se impuso un candidato neoliberal, que retomó la orientación que se intenta imponer desde la dictadura de 1976-83. Aunque el tiempo transcurrido es muy poco, se 
perfila un cambio radical. Fuerte ampliación de la insolvencia social frente al consumo de la ciudad por crecimiento del desempleo, baja del salario real, eliminación de subsidios a los servicios urbanos y disminución de los pocos créditos para vivienda que se ofrecían. Lo anterior, junto una nueva ola de endeudamiento externo y subordinación al capital financiero, acompañados de un giro hacia la represión de la protesta social, muestran una política de fortalecimiento de la concentración económica y de aumento de la pobreza.

Pedro Pírez es Doctor en Derecho y Ciencias Sociales por la Universidad Nacional de Córdoba. Investigador Principal del CONICET; profesor en el Doctorado en Ciencias Sociales y la Maestría en Gestión Ambiental Metropolitana en la Universidad de Buenos Aires $\$ ptpirez@gmail.com

\section{Referencias}

1. AZPIAZU, D. Privatización del agua y el saneamiento en Argentina: El caso paradigmático de Aguas Argentinas S.A, VertigO - revue électronique en sciences de l'environnement, http://vertigo.revues.org/9730; DOI: 10.4000/vertigo.9730. 2010.

2. BAER, L; y DUARTE J. I. Construcción de vivienda popular y regulación del mercado inmobiliario. Sobre la política de vivienda del 'primer peronismo' en la metrópolis de Buenos Aires. Realidad Económica, Buenos Aires N 263. 2011, pp 94-114.

3. BASUALDO, E. Estudios de Historia Económica Argentina. Desde mediados del siglo XX a la actualidad. Buenos Aires: Siglo XXI. 2010, 495 p.

4. CANITROT, A. La disciplina como objetivo de la política económica. Un ensayo sobre el programa económico del gobierno argentino desde 1976. Estudios CEDES, Buenos Aires, Vol. 2, No 6, 1979, PP 34, 3-34 p.

5. CASTELLS, M. La ciudad informacional. Tecnologías de la información, reestructuración económica y el proceso urbano. Madrid: Alianza Editorial. 1995, $504 \mathrm{p}$. 
6. CICCOLELLA, P. Grandes inversiones y dinámicas metropolitanas. Buenos Aires: ¿Ciudad global o ciudad dual del siglo XXI? Mundo Urbano, Bernal, No. 5. 2000. http://www.mundourbano.unq.edu.ar/index.php/ano-2000/41-numero-5--septiembre/58-2-grandes-inversiones-y-dinamicas-metropolitanas-buenos-aires

7. CLICHEVSKY, N. Política urbana y sector inmobiliario. In: CLICHEVSKY, N., PREVOT-SCHAPIRA M. F.; SCHNEIER G.. Loteos populares, sector inmobiliario y gestión local en Buenos Aires, Buenos Aires: Cuadernos del CEUR, Buenos Aires. 1990. 181 p. 3-82. 1990.

8. CLICHEVSKY, N. Políticas de regularización en Argentina: entre la euforia y la frustración. Buenos Aires: mimeo. 1999

9. CRAVINO, M. C. Las villas de la ciudad. Mercado e informalidad urbana. Los Polvorines: UNGS. 2006, 280 p.

10. CUENYA, B. Grandes proyectos urbanos, cambios en la centralidad urbana y conflictos de intereses. Notas sobre la experiencia argentina. In: CUENYA, B., NOVAIS, P.; VAINER C. (comp.). Grandes proyectos urbanos. Miradas críticas sobre la experiencia argentina y brasileña, Buenos Aires: Café de las Ciudades. 2012. 380 pp. 27-66.

11. GUTIÉRREZ, A. La gestión del transporte metropolitano en Buenos Aires: desafíos para una agenda sobre movilidad urbana. In: SCHTEINGART, M.; PÍREZ, P. (Coord.). Dos grandes metrópolis latinoamericanas: Ciudad de México y Buenos Aires. Una perspectiva comparativa. México: El Colegio de México, 2015. 365 pp. 319-362.

12. JANOSCHKA, M. El nuevo modelo de la ciudad latinoamericana: fragmentación y privatización. EURE, Santiago, 28(85). 2002. 11-20 pp.

13. JANOSCHKA, M. Nordelta - ciudad cerrada. El análisis de un nuevo estilo de vida en el Gran Buenos Aires. Scripta Nova, Revista Electrónica de Geografía y Ciencias Sociales, Barcelona, VII (146). 2003. http://www.ub.edu/geocrit/sn/ sn-146(121).htm

14. LENTINI, M. Transformaciones de la cuestión social habitacional: principales enfoques y perspectivas. El caso de Argentina en el contexto latinoamericano. Economía, Sociedad y Territorio, Toluca. Vol. VIII, No 27. 2008. 661-692 pp.

15. MERKLEN, D. Pobres ciudadanos. Las clases populares en la era democrática (Argentina, 1983-2003), Buenos Aires: Gorla. 2005. 218 pp.

16. MERKLEN, D. Un pobre es un pobre. La sociabilidad en el barrio: entre las condiciones y las prácticas" In. PÍREZ, P. (edit.) Buenos Aires, la formación del presente, Quito: OLACHI. 2009. 304 pp 83-117. 
17. MIGNAQUI, I.; SZAJNBERG, D. Tendencias en la organización del espacio residencial en la Región Metropolitana de Buenos Aires en los noventa", In BERTONCELLO, R. et al. (comps.) Procesos territoriales en Argentina y Brasil. Universidad de Buenos Aires, Buenos Aires.2003, pp 350, 91-115.

18. PÍREZ, P. Servicios urbanos y Equidad en América Latina. Un panorama con base en algunos casos. Serie Medio Ambiente y Desarrollo, 26. Santiago de Chile: CEPAL. 2000, 86 p.

19. PÍREZ, P.. La urbanización en América Latina: Las heterogeneidades en su producción y resultados. In I Congreso Latinoamericano de Teoría Social, Buenos Aires, 19-21 de agosto.2015

20. PÍREZ, P. Las sombras de la luz. Distribución eléctrica, configuración urbana y pobreza en la Región Metropolitana de Buenos Aires. Buenos Aires, EUDEBA. 2009, p 294.

21. PÍREZ, P. Gestión de servicios y calidad urbana en la ciudad de Buenos Aires. In EURE, Vol. XXV, Diciembre, No.7, Santiago de Chile. 1999, p.125-139.

22. PÍREZ, P. Buenos Aires metropolitana. Política y gestión de la ciudad. Centro Editor de América Latina-CENTRO, Buenos Aires. 1994. 184 p.

23. PÍREZ, P. La configuración metropolitana de Buenos Aires: expansión, privatización y fragmentación. In.: Realidad Económica, Buenos Aires, 208. 2004, p 111-134.

24. PÍREZ, P., et al. El sistema urbano-regional de redes de servicios e infraestructuras. Materiales para su estudio, La Plata: Editorial UNLP. 2003

25. PÍREZ, P., GITELMAN, N.; BONNAFÉ, J. Consecuencias políticas de la privatización de los servicios urbanos en la ciudad de Buenos Aires. In.: Revista Mexicana de Sociología, Vol. 61, No. 4. 1999, pp. 23-42.

26. PRÉVOT SCHAPIRA, M. F.; SCHNEIER G. Poder local y gestión de la tierra. In. CLICHESKY, N. et. Al. Loteos populares, sector inmobiliario y gestión local en Buenos Aires. El caso del Municipio de Moreno, Buenos Aires: Cuadernos del CEUR 29. 1990. 181 p. 83-181.

27. PUCCIARELLI, A. (coord.) Empresarios, tecnócratas y militares. La trama corporativa de la última dictadura. Buenos Aires: Siglo XXI, p 382.

28. RAPOPORT, Mario. Historia económica, política y social de la Argentina (1880-2003). Buenos Aires: Emecé. 1037 p.

29. RÍOS, D.; PÍREZ, P. Urbanizaciones cerradas en áreas inundables del municipio de Tigre: iproducción de espacio urbano de alta calidad? In.: EURE, № 101, 2008, 99-119 p. 
30. SOCOLOFF, I. Reflexiones en torno a las relaciones entre empresa, estado y ciudad: Un estudio a partir del caso IRSA en Buenos Aires (1991-2012). 2013. 338. Tesis (Doctorado en Ciencias Sociales), Facultad de Ciencias Sociales, Universidad de Buenos Aires.

31. TORRES, H. El mapa social de Buenos Aires (1940-1990). Buenos Aires: Facultad de Arquitectura, Diseño y Urbanismo, Universidad de Buenos Aires. 2006, p. 50.

32. VARELA, O.; FERNÁNDEZ, R. El retorno del Estado. In.: CRAVINO, M. C. (org.). Construyendo barrios. Transformaciones socioterritoriales a partir de los Programas Federales de Vivienda en el Área Metropolitana de Buenos Aires (2004-2006). Buenos Aires: Ciccus-UNGS, 2012. 400 pp. 15-48.

33. VIDAL-KOPPMANN, S. Transformaciones socio-territoriales de la Región Metropolitana de Buenos Aires en la última década del siglo XX: la incidencia de las urbanizaciones privadas en la fragmentación de la periferia. In.: VIII Seminario Red Iberoamericana de Investigadores sobre Globalización y Territorio, Río de Janeiro. 2004

34. YUJNOVSKY, O. Políticas de vivienda en la ciudad de Buenos Aires (18801914). In.: Desarrollo Económico. Buenos Aires, Vol. 14, No. 54 (Jul. - Sep., 1974), p. 327-372.

35. YUJNOVSKY, O. Claves políticas del problema habitacional argentino. 1955/1981. Buenos Aires: Grupo Editor Latinoamericano. 1984. 411 p.

Recebido em: 12/02/2016

Aceite Final: 20/04/2016 